\title{
Conservation genetics and phylogeography of endangered and endemic shrub Tetraena mongolica (Zygophyllaceae) in Inner Mongolia, China
}

\author{
Xue-Jun Ge ${ }^{1 \dagger}$, Chi-Chuan Hwang ${ }^{2 \dagger}$, Zin-Huang Liu ${ }^{3 \dagger}$, Chi-Chun Huang ${ }^{4 \dagger}$, Wei-Hsiang Huang ${ }^{3}$, Kuo-Hsiang Hung ${ }^{5}$, \\ Wei-Kuang Wang ${ }^{4^{*}}$, Tzen-Yuh Chiang ${ }^{4^{*}}$
}

\begin{abstract}
Background: Tetraena mongolica (Zygophyllaceae), an endangered endemic species in western Inner Mongolia, China. For endemic species with a limited geographical range and declining populations, historical patterns of demography and hierarchical genetic structure are important for determining population structure, and also provide information for developing effective and sustainable management plans. In this study, we assess genetic variation, population structure, and phylogeography of T. mongolica from eight populations. Furthermore, we evaluate the conservation and management units to provide the information for conservation.

Results: Sequence variation and spatial apportionment of the atpB-rbcL noncoding spacer region of the chloroplast DNA were used to reconstruct the phylogeography of T. mongolica. A total of $880 \mathrm{bp}$ was sequenced from eight extant populations throughout the whole range of its distribution. At the cpDNA locus, high levels of genetic differentiation among populations and low levels of genetic variation within populations were detected, indicating that most seed dispersal was restricted within populations.

Conclusions: Demographic fluctuations, which led to random losses of genetic polymorphisms from populations, due to frequent flooding of the Yellow River and human disturbance were indicated by the analysis of BEAST skyline plot. Nested clade analysis revealed that restricted gene flow with isolation by distance plus occasional long distance dispersal is the main evolutionary factor affecting the phylogeography and population structure of $T$. mongolica. For setting a conservation management plan, each population of $T$. mongolica should be recognized as a conservation unit.
\end{abstract}

\section{Background}

Genetic variation within and among natural populations is crucial for the long-term survival of a species. An accurate estimate of the level and distribution of genetic diversity of threatened species provides fundamental information in designing conservation programs [1,2]. Tetraena mongolica Maxim, a monotypic genus of the Zygophyllaceae, is endemic to the western part of Inner Mongolia around the basin of the Yellow River [3], and

\footnotetext{
* Correspondence: weikuangwang@gmail.com; tychiang@mail.ncku.edu.tw + Contributed equally

${ }^{4}$ Department of Life Sciences, National Cheng-Kung University, Tainan 701, Taiwan

Full list of author information is available at the end of the article
}

is also subjected as nationally endangered in China [4]. Plants of T. mongolica, up to $0.5 \mathrm{~m}$ in height, flower from mid-May till early June, and set fruits in July. The species is restrictedly distributed in the western Gobi, the largest desert in Asia characterized by extreme low annual rainfall [3], where T. mongolica with a fully developed root system is well adapted and becomes locally dominant. T. mongolica plays an important ecological role as windbreak for stabilizing river bank [5]. Nevertheless, it has been used as firewood, locally called as "oil firewood" because its stems are combustible even in fresh state due to containing high levels of triacylglycerol [6]. Human's overexploitation has inevitably caused a dramatic decline of the species.

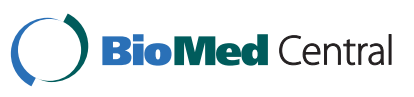


Previous studies have been focusing on the biological characters causing the population decline of T. mongolica. As the high rate of ovule abortion after anthesis [7], the seed-set of $T$. mongolica was quite low (1.3 $2.8 \%)$ in the natural populations $[8,9]$. Previous population genetic researches based on allozyme and ISSR data revealed medium levels of genetic differentiation among populations of $T$. mongolica $[3,10]$.

Understanding levels and spatial partitioning of genetic polymorphisms in an endangered species provides sufficient information for conservation practices. This kind of researches has become increasingly popular in the recent years, with the development of analytical methods to take phylogenetic distinctiveness into account when setting conservation priorities $[11,12]$. During the past few decades, the theoretical framework of population genetics and empirical data gathered with the help of molecular genetic methods have been widely used in conservation biology [13]. Given a haploid nature and a low frequency of genetic recombination, molecular markers of organelle DNA have been long used for phylogenetic reconstruction at various taxonomic levels, conservation genetics, and assessing the migratory routes of species $[14,15]$. Although chloroplast DNA evolves relatively slowly, moderate to high levels of genetic variation have frequently been detected in some noncoding spacers within and among species [16-18]. With maternal inheritance [19], cpDNA is suitable for investigating processes associated with seed dispersal, such as range expansions [20] and the contribution of seed movement to total gene flow [21,22].

For endemic species with a limited geographical range and declining populations, historical patterns of demography and hierarchical genetic structure are important for determining population structure, and also provide information for developing effective and sustainable management plans [23]. In this study, we investigated genetic variation, population structure, and phylogeography of $T$. mongolica from eight populations throughout the entire distribution range. Several aims are pursued: 1) to examine the levels of genetic variation within and between populations, 2) to reconstruct phylogeographical patterns and examine the extent of genetic differentiation among populations, and 3 ) to identify the conservation and management units based on genetic evidence, to provide the information for the development of effective and efficient conservation practices for this species.

\section{Results}

\section{Genetic diversity and cpDNA phylogeny of $T$. mongolica}

No within-individual variation was detected in the noncoding spacer between $a t p \mathrm{~B}$ and $r b c \mathrm{~L}$ genes of the chloroplast DNA. Identical sequences were obtained from five clones derived from the same amplification reaction, indicating no PCR artifacts caused by Taq polymerase or sequencing errors. The $a t p \mathrm{~B}-r b c \mathrm{~L}$ intergenic region of cpDNA in T. mongolica varied from 872 to 880 base pairs (bp) in length. The cpDNA sequences were aligned with a consensus length of $881 \mathrm{bp}$, of which 46 sites (5.2\%) were variable.

The chloroplast spacer is A/T rich with an average content of $73.6 \%$, which is consistent with the nucleotide composition of most noncoding spacers and pseudogenes because of low functional constraints [24]. In total, 38 haplotypes (GenBank accession numbers of HQ142910-HQ142986) were identified from 77 individuals of $T$. mongolica, with an estimated haplotype diversity of $h=0.962 \pm 0.009$ (Table 1; Figure 1). Except for the monomorphic population of YKBLG, haplotype diversity varied across populations, ranging between 0.378 (GLS) and 1.000 (HN). Low levels of nucleotide difference were detected within the whole species $(\theta=$ $0.00447 \pm 0.0003)$ and within populations, ranging from $\theta=0.00099$ (TST) to 0.00405 (HN).

A neighbor-joining tree obtained using MEGA recovered eight cpDNA clades (Figure 2). Most of the populations contained only one clade in the genetic composition, except for the populations XD and HN. Apparently, most genetic variation resides between populations of T. mongolica.

\section{Nested clade analysis, phylogeography and population differentiation}

A nested clade analysis was accomplished by linking nucleotide haplotypes in a hierarchical manner based on mutational changes. After linking the haplotypes into a clade, closely related clades were linked further to form a higher-level group; via such hierarchical linking, a nested network was drawn (Figure 3). In total, 38 haplotypes (H1-H38) and 8 clades, 1-1 to 1-8, were identified. The distribution of haplotypes and clades in populations was indicated in Tables 2 and 3. Clades 1 1 to $1-3$ were clustered into clade $2-1$, which was further grouped with clade 2-2 into a higher-level clade 3-1. Likewise, clades 2-3 and 2-4, which consisted of clades $1-4$ to $1-5$ and $1-6$ to $1-7$, respectively, were clustered and nested with clade $2-5$ in the higher-level clade 3-2. Clades 3-1 and 3-2 corresponding to clades G-H and A-E of the NJ tree, respectively, were identified. The former is distributed in the southern part of the distributional range, while the latter is in the northern part. The topology showing geographical division is shared by the minimum spanning network and the NJ tree. Most populations were genetically differentiated, as most haplotypes were private within populations except for H11, which were shared by populations TST and HN (Table 2). 
Table 1 Population locations, numbers of sample size and site coordinate of Tetraena mongolica, the estimates of haplotype diversity $(h)$ and nucleotide difference $(\theta)$ within populations on cpDNA sequences.

\begin{tabular}{|c|c|c|c|c|c|c|c|c|}
\hline Population & Code & Site coordinate & Elevation & $\begin{array}{l}\text { Sample } \\
\text { size (N) }\end{array}$ & $\begin{array}{l}\text { Number of } \\
\text { haplotypes }\end{array}$ & $\begin{array}{l}\text { Polymorphic } \\
\text { sites (S) }\end{array}$ & $h \pm S D$ & $\theta \pm \mathrm{SD}$ \\
\hline 1. Shizuishan & SZS & $106^{\circ} 49^{\prime} \mathrm{E} 39^{\circ} 25^{\prime} \mathrm{N}$ & $1130 \mathrm{~m}$ & 10 & 4 & 4 & $0.733 \pm 0.120$ & $0.00146 \pm 0.00037$ \\
\hline 2. Hainanqu & $\mathrm{HN}$ & $106^{\circ} 54^{\prime} \mathrm{E} 39^{\circ} 33^{\prime} \mathrm{N}$ & $1280 \mathrm{~m}$ & 10 & 10 & 9 & $1.000 \pm 0.045$ & $0.00405 \pm 0.00041$ \\
\hline 3. Qianlishan & GLS & $106^{\circ} 50^{\prime} \mathrm{E} 39^{\circ} 50^{\prime} \mathrm{N}$ & $1170 \mathrm{~m}$ & 10 & 3 & 7 & $0.378 \pm 0.181$ & $0.00160 \pm 0.00105$ \\
\hline 4. Xindi & $X D$ & $106^{\circ} 46^{\prime} \mathrm{E} 39^{\circ} 52^{\prime} \mathrm{N}$ & 1090 m & 10 & 7 & 9 & $0.933 \pm 0.062$ & $0.00334 \pm 0.00069$ \\
\hline 5. Yikebulage & YKBLG & $106^{\circ} 49^{\prime} \mathrm{E} 40^{\circ} 05^{\prime} \mathrm{N}$ & 1070 m & 8 & 1 & 0 & $0.000 \pm 0.000$ & $0.00000 \pm 0.00000$ \\
\hline 6. Taositu & TST & $106^{\circ} 54^{\prime} \mathrm{E} 40^{\circ} 09^{\prime} \mathrm{N}$ & $1070 \mathrm{~m}$ & 10 & 4 & 3 & $0.644 \pm 0.152$ & $0.00099 \pm 0.00030$ \\
\hline 7. Muoshigou & MSG & $107^{\circ} 04^{\prime} \mathrm{E} 40^{\circ} 07^{\prime} \mathrm{N}$ & 1380 m & 10 & 4 & 3 & $0.733 \pm 0.101$ & $0.00110 \pm 0.00025$ \\
\hline 8. Balagong & $\mathrm{BLG}$ & $107^{\circ} 03^{\prime} \mathrm{E} 40^{\circ} 16^{\prime} \mathrm{N}$ & 1100 m & 9 & 6 & 9 & $0.833 \pm 0.016$ & $0.00249 \pm 0.00066$ \\
\hline Overall & & & & 77 & 38 & 44 & $0.962 \pm 0.009$ & $0.00447 \pm 0.00030$ \\
\hline
\end{tabular}

A nested contingency analysis detected significant geographical associations within several clades (2-1, 2-3, 2-4, 3-1 and 3-2) and the whole cladogram. The phylogeographical inferences are listed in Figure 4. Most tipclades were restricted to unique regions, whereas basal interior clade 1-4 was widespread (Table 3, Figure 3). The results agree with the hypothesis of constrained seed dispersal of the species. The deduced $\mathrm{Nm}$ of 0.040.71 and $F_{S T}$ of 0.38-0.90 indicated high levels of genetic differentiation between all populations, with three exceptional pairs of HN-TST, HN-XD and XD-TST
(Table 4). An "isolation by distance" model across eight populations of the species was supported by a regression test between $N m$ values and geographical distance $(\mathrm{R}=$ 0.772, $\mathrm{P}<0.05)$.

Relative values of $D c$ and $D n$ for each clade representing contemporary distributions of haplotypes were used to interpret historical and contemporary gene flow processes (Figure 4). Restricted gene flow with isolation by distance was the primary process responsible for the present-day distribution in Inner Mongolia (total cladogram), also inferred for clade 2-3. While some other

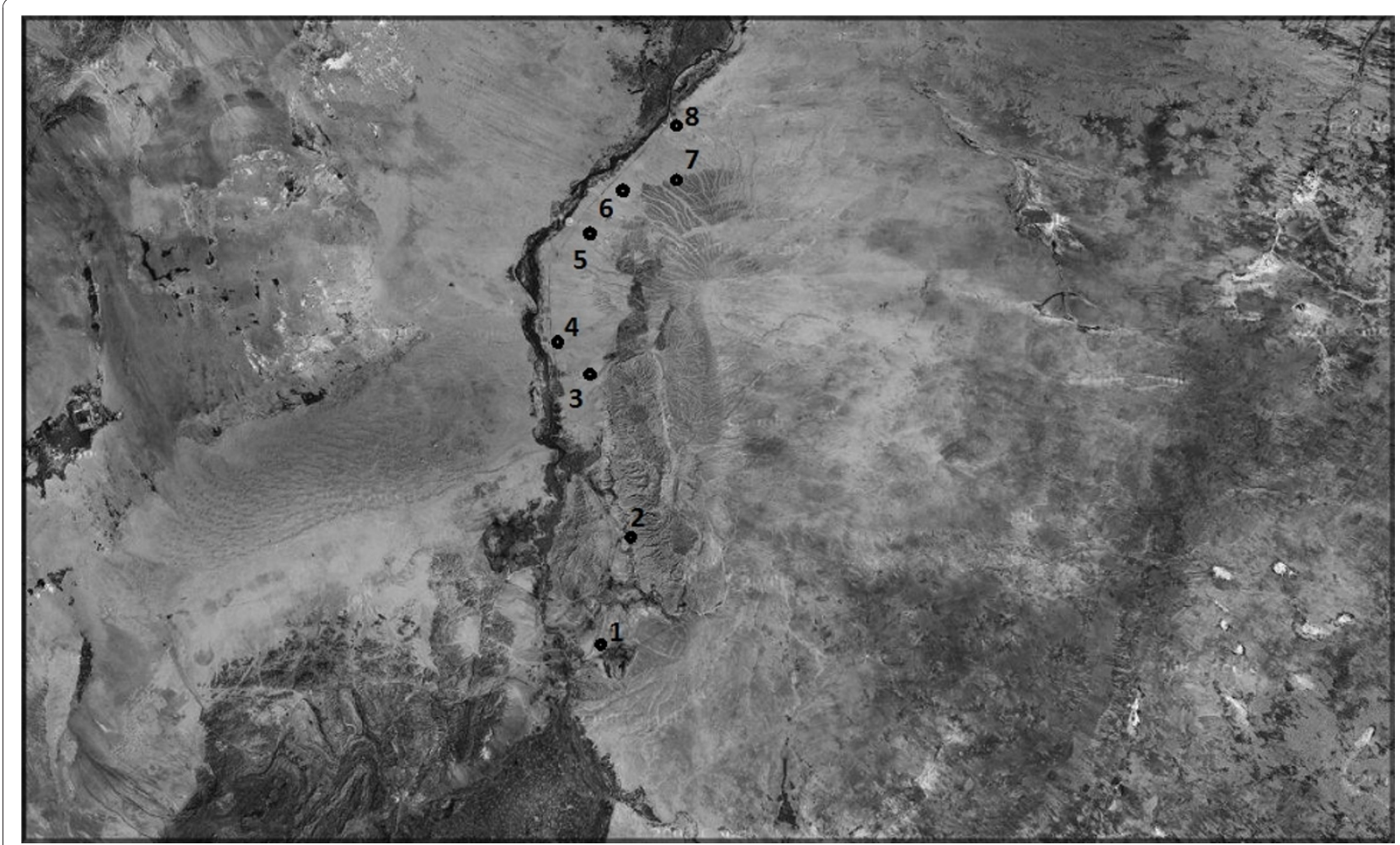

Figure 1 Map showing population locations of Tetraena mongolica sampled. Population names are 1. Shizuishan, 2. Hainanqu, 3 . Qianlishan, 4. Xindi, 5. Yikebulage, 6. Taosita, 7. Muoshigou, 8. Balagong. 


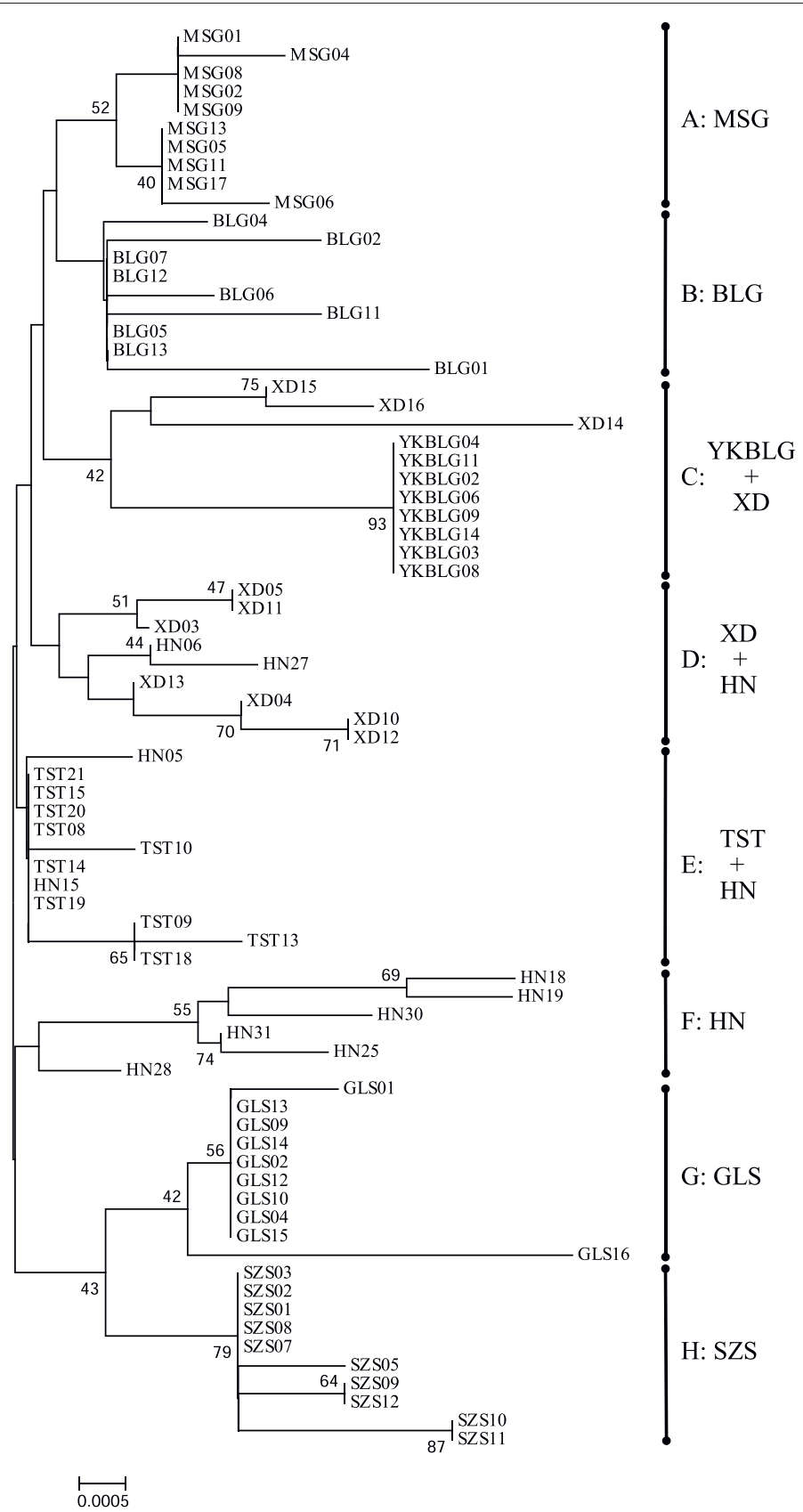

Figure 2 Neighbor-joining tree of Tetraena mongolica based on sequences of the atpB-rbcL intergenic spacer of cpDNA. Numbers at nodes are bootstrap values. See Table 1 for the acronyms of population names.

different inferences, like long distance colonization and past fragmentation were detected at clade clades 3-1 and 3-2, respectively. This result shows limited seed dispersal of this species, while with occasional long distance dispersal [25].

\section{Population demography pattern of $T$. mongolica}

Historical population dynamics of T. mongolica was estimated using Bayesian skyline plots, a coalescent Markov chain Monte Carlo method that does not require an assumed parametric model of demographic history. 


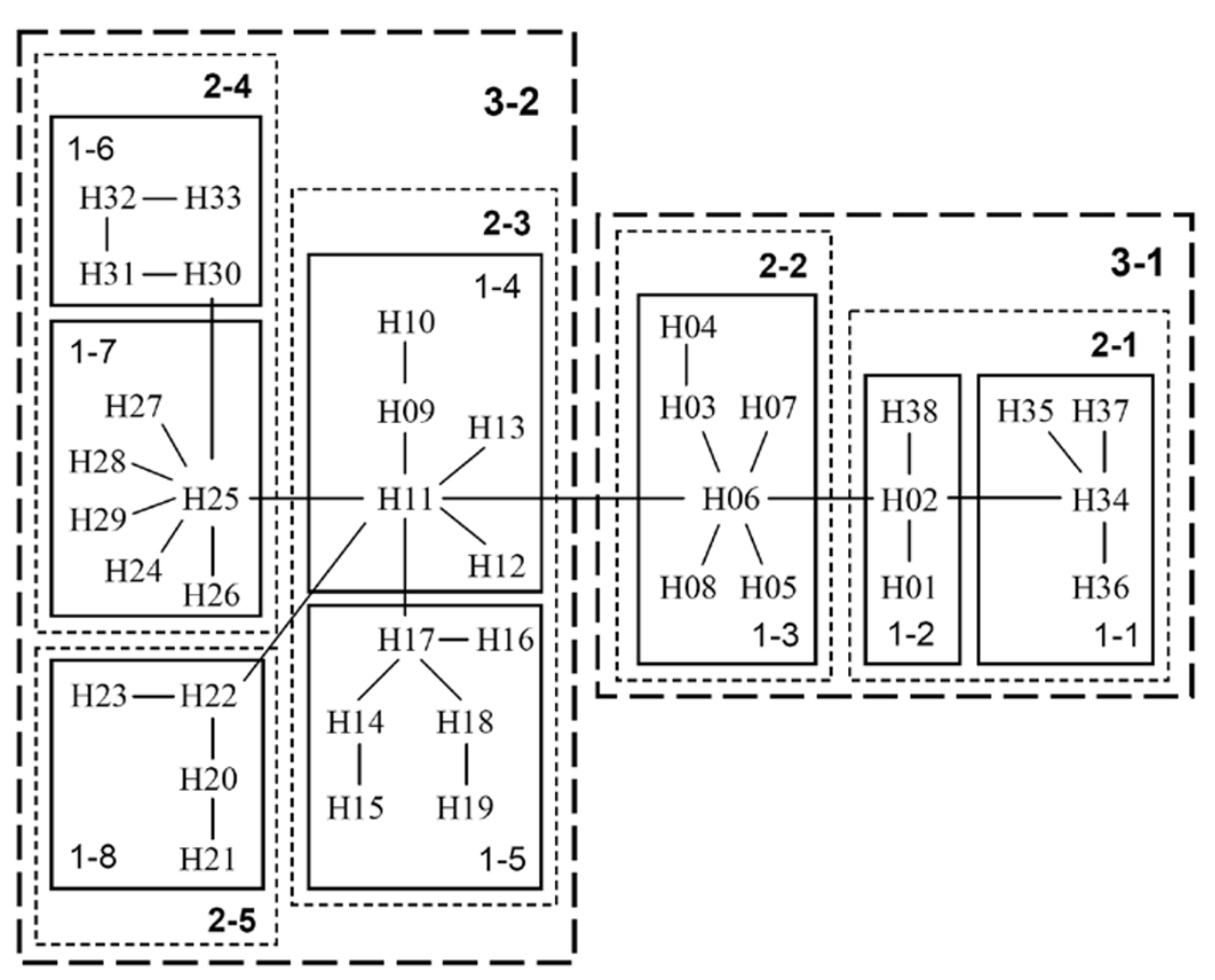

Figure 3 Minimum-spanning network based on mutations between haplotypes of the atpB-rbcL noncoding spacer of $c p D N A$ of Tetraena mongolica.

The skyline diagrams, which summarize instantaneous estimates of effective population size, showed recent population decline for $T$. mongolica over the last sixteen thousand years (Figure 5). The shape of the skyline diagram conforms to its known history. That is, habitat destruction and misapplication of human activity and the frequent flooding of the Yellow River may have caused a decline in T. mongolica population size.

\section{Discussion}

Genetic variation of the atpB-rbcL noncoding spacer of cpDNA in T. mongolica

In this study, we investigated the phylogeographical pattern and population structure of endangered T. mongolica in western Inner Mongolia. In total, 38 haplotypes were detected at the cpDNA $a t p \mathrm{~B}-r b c \mathrm{~L}$ locus in T. mongolica. The level of genetic variation of cpDNA is comparable to that of other endangered shrub plants, e.g., Dunnia sinensis $(\theta=0.0022)$ [26], and Hygrophila pogoncalyx $(\theta=0.00343)$ [17], but is lower compared to other endangered species, e.g., $\theta=0.01018$ for the cpDNA trnD-trn T spacer of Cunninghamia konishii [27], and $\theta=0.01268$ for the cpDNA $a t p \mathrm{~B}-r b c \mathrm{~L}$ spacer of Cycas taitungensis [28]. The twofold lower nucleotide diversity to above endangered species in T. mongolica may be ascribed to its extremely small effective population size associated with the low seed set in wild (1.3$2.8 \%)$ [9].

Recent habitat loss has reduced the number and size of T. mongolica populations [10]. Small populations of narrowly distributed species are expected to exhibit low levels of genetic variation, but high levels of genetic differentiation among populations, which were all detected in this species (Table 4) [2]. Interestingly, different levels of genetic variation were detected in different populations. The HN and XD populations possessed more haplotypes and higher genetic diversity than others, whereas YKBLG population displayed genetic homogeneity (Table 1). The lack of genetic variability in some populations, e.g. SZS, MSG and TST, near threefold lower in nucleotide diversity, was likely associated with frequently human activities. In contrast, some populations of T. mongolica experienced relatively little disturbance due to low accessibilities $[3,10]$.

Our previous study revealed medium levels of genetic differentiation among populations of T. mongolica based on ISSR data [10]. In contrast, in cpDNA spacer higher genetic differentiation was detected between populations than in ISSR fingerprinting. The difference may be highly associated with the reproductive characteristics of 
Table 2 Individual number and geographical distribution of haplotypes in populations of Tetraena mongolica based on cpDNA data.

\begin{tabular}{|c|c|c|c|c|c|c|c|c|c|}
\hline & SZS & $\mathrm{HN}$ & GLS & $X D$ & YKBLG & TST & MSG & BLG & Total \\
\hline $\mathrm{H} 01$ & & & 1 & & & & & & 1 \\
\hline $\mathrm{H} 02$ & & & 8 & & & & & & 8 \\
\hline $\mathrm{H} 03$ & & 1 & & & & & & & 1 \\
\hline $\mathrm{H} 04$ & & 1 & & & & & & & 1 \\
\hline H05 & & 1 & & & & & & & 1 \\
\hline H06 & & 1 & & & & & & & 1 \\
\hline H07 & & 1 & & & & & & & 1 \\
\hline H08 & & 1 & & & & & & & 1 \\
\hline H09 & & & & & & 1 & & & 1 \\
\hline $\mathrm{H} 10$ & & & & & & 2 & & & 2 \\
\hline $\mathrm{H} 11$ & & 1 & & & & 6 & & & 7 \\
\hline $\mathrm{H} 12$ & & & & & & 1 & & & 1 \\
\hline $\mathrm{H} 13$ & & 1 & & & & & & & 1 \\
\hline $\mathrm{H} 14$ & & 1 & & & & & & & 1 \\
\hline H15 & & 1 & & & & & & & 1 \\
\hline $\mathrm{H} 16$ & & & & 2 & & & & & 2 \\
\hline $\mathrm{H} 17$ & & & & 2 & & & & & 2 \\
\hline $\mathrm{H} 18$ & & & & 2 & & & & & 2 \\
\hline $\mathrm{H} 19$ & & & & 1 & & & & & 1 \\
\hline $\mathrm{H} 20$ & & & & & & & 4 & & 4 \\
\hline $\mathrm{H} 21$ & & & & & & & 1 & & 1 \\
\hline $\mathrm{H} 22$ & & & & & & & 4 & & 4 \\
\hline $\mathrm{H} 23$ & & & & & & & 1 & & 1 \\
\hline $\mathrm{H} 24$ & & & & & & & & 1 & 1 \\
\hline $\mathrm{H} 25$ & & & & & & & & 4 & 4 \\
\hline $\mathrm{H} 26$ & & & & & & & & 1 & 1 \\
\hline $\mathrm{H} 27$ & & & & & & & & 1 & 1 \\
\hline $\mathrm{H} 28$ & & & & & & & & 1 & 1 \\
\hline $\mathrm{H} 29$ & & & & & & & & 1 & 1 \\
\hline $\mathrm{H} 30$ & & & & & 8 & & & & 8 \\
\hline H31 & & & & 1 & & & & & 1 \\
\hline H32 & & & & 1 & & & & & 1 \\
\hline H33 & & & & 1 & & & & & 1 \\
\hline H34 & 5 & & & & & & & & 5 \\
\hline H35 & 1 & & & & & & & & 1 \\
\hline H36 & 2 & & & & & & & & 2 \\
\hline H37 & 2 & & & & & & & & 2 \\
\hline H38 & & & 1 & & & & & & 1 \\
\hline Total & 10 & 10 & 10 & 10 & 8 & 10 & 10 & 9 & 77 \\
\hline
\end{tabular}

the species. It has been known that gene flow of seed plants occurs either via pollen prior to fertilization or seeds. In this study, T. mongolica is primarily pollinated by insects [29]. Gene flow between populations via pollen would be limited by the migratory capacity of pollinators. In addition, seed dispersal of seeds from schizocarp, a dry fruit developing from four carpels, is constrained by gravity [29], likely resulting in most seed dispersal confined to short distances. With maternal inheritance and haploid nature, chloroplast DNA is suitable for estimating the contribution of seed movement to total gene flow [21], whereas, ISSRs represent nuclear DNA, mostly carried and dispersed by pollen dispersal [30]. In this study, higher genetic differentiation between all populations in cpDNA than in ISSR is likely ascribed to limited seed dispersal.

The BEAST skyline plot for cpDNA spacer identified a recent population decline ever since sixteen thousand years before present likely associated with human destruction as T. mongolica has long been used as firewood (Figure 5) [6]. Ecologically, this plant is still one of the dominant shrubs in Inner Mongolia. Through the analysis of skyline plot, we were able to recover the history of a long term human disturbance that caused a decline in population size of $T$. mongolica.

Another major factor that shaped the phylogeography and population demography is the frequent flooding of the Yellow River, the second longest river in China [31]. The floods not only eroded river banks, but resulted in many habitats submerged, inevitably leading to population extinction. In addition to bank erosion, the Yellow River is well known for its heavy load of silt. Soil deposits elevate the riverbed and cause flows between natural levees. The river may break out of the levees into the surrounding lower flood plain and adopt a new route. Records indicate that the events have occurred about once every century [32]. Such devastations caused dramatic changes of flora and fauna along the Yellow River. Geological records indicate that the river's levees were breached more than 1,500 times and its course changed 26 times in the last 3,000 years [32]. Given such frequent flooding, T. mongolica would have experienced demographic fluctuations over and over. That is, severe periodical population bottlenecks followed by subsequent demographic expansion would elevate genetic drift effects and lead to a loss of genetic variation $[33,34]$.

\section{Phylogeography and conservation of $T$. mongolica}

In this study, gene genealogy of cpDNA in T. mongolica was recovered (Figures 2 and 3). Eight cpDNA clades were identified in the NJ tree. Most of the populations contained only one clade in the genetic composition, displaying a pattern of most genetic variation residing between populations. Nested contingency analysis discriminating the geographical associations of haplotypes and clades provides further insights into historical events that shaped the phylogeography (Figure 4). At the total cladogram, restricted levels of $D c$ vs. a large $D n$ illustrates restricted gene flow with isolation by distance as the primary process responsible for the present-day distribution of T. mongolica in Inner Mongolia. As cpDNA is maternally inherited, this inference 
Table 3 Number of individuals and geographical distribution of clades in populations of Tetraena mongolica based on cpDNA data.

\begin{tabular}{|c|c|c|c|c|c|c|c|c|c|}
\hline Clade $^{a}$ & Individual (n) & SZS & $\mathrm{HN}$ & GLS & $X D$ & YKBLG & TST & MSG & BLG \\
\hline $1-1$ & 10 & 10 & & & & & & & \\
\hline $1-2$ & 10 & & & 10 & & & & & \\
\hline $2-1$ & $20(26.0 \%)$ & 10 & & 10 & & & & & \\
\hline $1-3$ & 6 & & 6 & & & & & & \\
\hline $2-2$ & $6(7.8 \%)$ & & 6 & & & & & & \\
\hline $3-1$ & $26(33.8 \%)$ & 10 & 6 & 10 & & & & & \\
\hline $1-4$ & 12 & & 2 & & & & 10 & & \\
\hline $1-5$ & 9 & & 2 & & 7 & & & & \\
\hline $2-3$ & $21(27.3 \%)$ & & 4 & & 7 & & 10 & & \\
\hline $1-6$ & 11 & & & & 3 & 8 & & & \\
\hline $1-7$ & 9 & & & & & & & & 9 \\
\hline $2-4$ & 20 (25.9\%) & & & & 3 & 8 & & & 9 \\
\hline $1-8$ & 10 & & & & & & & 10 & \\
\hline $2-5$ & $10(13.0 \%)$ & & & & & & & 10 & \\
\hline $3-2$ & $51(66.2 \%)$ & & 4 & & 10 & 8 & 10 & 10 & 9 \\
\hline Total & 77 & 10 & 10 & 10 & 10 & 8 & 10 & 10 & 9 \\
\hline
\end{tabular}

indicates limited seed dispersal. Besides, long distance colonization was also observed in clade 3-1, a common phenomenon occurring over glacial maxima [25]. Furthermore, past fragmentation observed in clade 3-2 was likely associated with the Yellow River flooding.

It is expected that endangered species that are narrowly distributed and own a small population size would have high risks of extinction, especially when gene flow between populations is restricted [1,35]. Another consequence of a small-sized population is the susceptibility to inbreeding, which reduces heterozygosity and the performance of various fitness-related traits, thereby substantially increasing the probability of extinction [36,37]. Given small sizes in the wild populations of

\begin{tabular}{|c|c|c|c|c|c|c|c|c|c|c|c|c|c|}
\hline Clade & Dc & Dn & Tip/interior & & Clade & Dc & Dn & Tip/interior & & Clade & Dc & Dn & Tip/interior \\
\hline \begin{tabular}{|l}
$1-1$ \\
$1-2$ \\
$\mathrm{I} / \mathrm{T}$ \\
\end{tabular} & $\begin{array}{l}0^{\mathrm{S}} \\
0^{\mathrm{S}} \\
0^{\mathrm{S}} \\
\end{array}$ & $\begin{array}{l}65.7^{\mathrm{L}} \\
61.3^{\mathrm{L}} \\
-4.8^{-}\end{array}$ & $\begin{array}{l}\text { Tip } \\
\text { Interior }\end{array}$ & $\rightarrow$ & $\begin{array}{l}2-1 \\
2-2 \\
\mathrm{I} / \mathrm{T} \\
\end{array}$ & $\begin{array}{l}63.4^{\mathrm{L}} \\
0^{\mathrm{S}} \\
-63.4^{\mathrm{S}} \\
\end{array}$ & $\begin{array}{l}59.2^{\mathrm{L}} \\
43.6^{\mathrm{S}} \\
-15.7^{\mathrm{S}} \\
\end{array}$ & $\begin{array}{l}\text { Tip } \\
\text { Interior }\end{array}$ & $\rightarrow$ & 3-1 & $55.3^{\mathrm{S}}$ & $95.8^{\mathrm{L}}$ & Tip \\
\hline $\begin{array}{l}1-4 \\
1-5 \\
\mathrm{I} / \mathrm{T} \\
\end{array}$ & $\begin{array}{l}61.4 \\
42.6^{\mathrm{S}} \\
18.9 \\
\end{array}$ & $\begin{array}{l}70.8^{\mathrm{L}} \\
67.0 \\
3.8 \\
\end{array}$ & $\begin{array}{l}\text { Interior } \\
\text { Tip }\end{array}$ & $\rightarrow$ & $2-3$ & 69.9 & $71.3^{\mathrm{L}}$ & Interior & & & & & \\
\hline $\begin{array}{l}1-6 \\
1-7 \\
\mathrm{I} / \mathrm{T} \\
\end{array}$ & $\begin{array}{l}30.4^{\mathrm{S}} \\
0^{\mathrm{S}} \\
-30.4^{\mathrm{S}} \\
\end{array}$ & $\begin{array}{l}59.4^{\mathrm{L}} \\
60.5^{\mathrm{L}} \\
1.1\end{array}$ & $\begin{array}{l}\text { Tip } \\
\text { Interior }\end{array}$ & $\rightarrow$ & $\begin{array}{l}2-4 \\
2-5 \\
\mathrm{I} / \mathrm{T} \\
\end{array}$ & $\begin{array}{l}59.9 \\
0^{\mathrm{S}} \\
30.0^{\mathrm{L}}\end{array}$ & $\begin{array}{l}62.3 \\
57.2^{2} \\
10.7^{\mathrm{L}} \\
\end{array}$ & $\begin{array}{l}\text { Tip } \\
\text { Tip }\end{array}$ & $\rightarrow$ & 3-3 & $65.6^{\mathrm{S}}$ & $82.4^{\mathrm{S}}$ & Tip \\
\hline
\end{tabular}

S: significantly small $\quad$ L: significantly large

\begin{tabular}{lll} 
Clade & \multicolumn{1}{c}{ Clade Key } & Inferences \\
\hline Clade 2-1 & $1.2 .11 .12 .13:$ Yes & Long distance colonization \\
Clade 2-3 & $1.2 .3 .4:$ No & Restricted gene flow with isolation by distance \\
Clade 2-4 & $1.2 .11 .12 .13:$ Yes & Long distance colonization \\
Clade 3-1 & $1.2 .11 .12:$ No & Contiguous range expansion \\
Clade 3-2 & $1.2 .3 .4 .9:$ No & Past fragmentation \\
Total cladogram & $1.2 .11 .17 .4:$ No & Restricted gene flow with isolation by distance \\
\hline
\end{tabular}

Figure 4 Result of the nested clade analysis. Clade (Dc) and nesting clade (Dn) distances are given for each level of the nesting design. Superscripts refer to significantly small $(S)$ or large (L) clade and nested clade distances. Inferences of current population structure and population history based on nested clade analysis and the interpretation key given in Templeton et al. (1995) are indicated at the bottom of the figure. 
Table 4 Pairwise comparisons of deduced Nm (below diagonal) and Fst (above diagonal) between populations of Tetraena mongolica based on cpDNA sequences.

\begin{tabular}{lcccccccc}
\hline & SZS & HN & GLS & XD & YKBLG & TST & MSG & BLG \\
\hline SZS & & 0.54 & 0.64 & 0.56 & 0.90 & 0.70 & 0.78 & 0.65 \\
HN & 0.42 & & 0.50 & 0.20 & 0.66 & 0.26 & 0.41 & 0.37 \\
GLS & 0.28 & 0.50 & & 0.65 & 0.86 & 0.65 & 0.73 & 0.60 \\
XD & 0.39 & 2.01 & 0.44 & & 0.68 & 0.27 & 0.47 & 0.38 \\
YKBLG & 0.06 & 0.26 & 0.04 & 0.24 & & 0.86 & 0.85 & 0.68 \\
TST & 0.21 & 1.44 & 0.27 & 1.36 & 0.08 & & 0.59 & 0.40 \\
MSG & 0.07 & 0.71 & 0.19 & 0.28 & 0.04 & 0.18 & & 0.45 \\
BLG & 0.13 & 0.68 & 0.33 & 0.41 & 0.12 & 0.37 & 0.30 &
\end{tabular}

T. mongolica, the maintenance of genetic diversity would be critical for the long-term survival of species in considering conservation strategies [38]. Historical demographic events in a species play an important role in determining the present-day geographic structure of intraspecific genetic variation [39]. In this study, given the high levels of population differentiation between populations and low levels of genetic diversity within populations of $T$. mongolica, for retaining the existing diversity, reservation regions covering major populations with high genetic variation should be established.
Habitat destruction and fragmentation would inevitably result in small and isolated populations [40,41], and increase the risk of population extinction. Today, many natural habitats of T. mongolica around the Yellow River have been destroyed or altered due to human overexploitation. In order to develop an effective strategy to conserve species, the Evolutionarily Significant Unit (ESU) needs to be defined. Various criteria for ESUs have been suggested, including reciprocal monophyly [23], adaptive variation [42], and reproductive separation [43]. Recognizing ESUs as reciprocally monophyletic groups ensures that the entire evolutionary heritage within species can be maintained and that populations belonging to different lineages can be managed separately [44]. In T. mongolica, given high levels of genetic differentiation and reciprocal monophyly between most populations and lower genetic variation within populations, each population should be treated as different evolutionarily significant units for conservation (Figure 2).

From another view, conservation efforts can be targeted to genetic hot spots where populations have high levels of genetic diversity $[17,45]$. Accordingly, $\mathrm{HN}$ and $\mathrm{XD}$ populations that owned higher genetic diversity near two-three folds than other populations (Table 1)

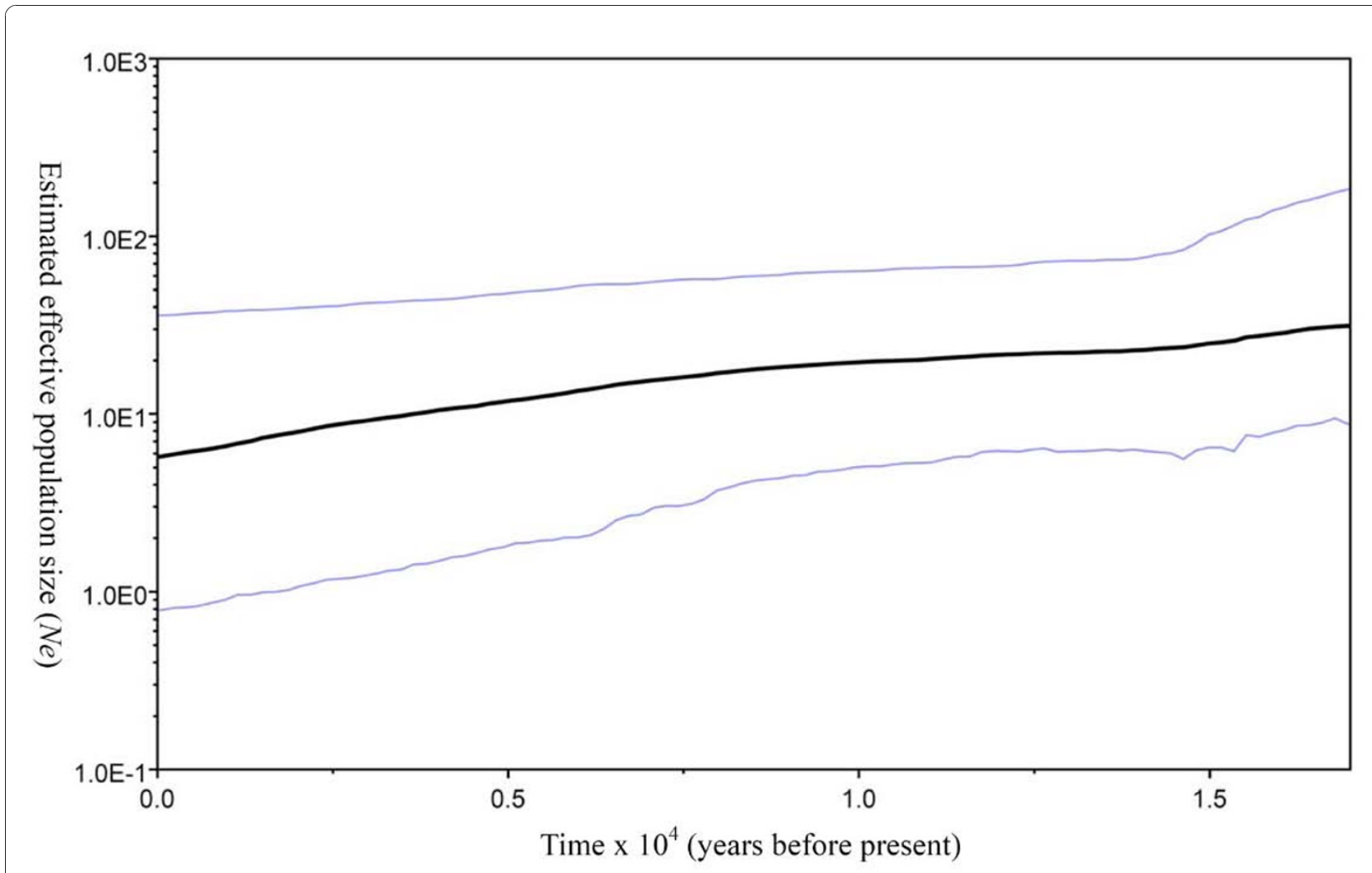

Figure 5 Median effective population size (thin lines indicate $95 \%$ highest posterior density interval) as estimated from cpDNA atpB$r b c L$ spacer sequence data in program BEAST using a Bayesian skyline plot technique. 
can be recognized as genetic hot spots of $T$. mongolica. The concept of genetic and ecological exchangeabilities is also central to the definitions of ESU [46]. Crandall et al. [44] emphasize that the ESU concept not only includes ecological data and genetic variation, but also considers the ecological and genetic exchangeabilities. In practice, the status of recent and historical genetic and ecological exchangeability between populations is considered. As the contemporary gene flow from the populations at genetic hot spots to other populations does not exist or cannot be determined, the populations at the genetic hot spots need to be treated as distinct conservation units for its unique genetic variation [44]. Accordingly, hotspots at $\mathrm{HN}$ and XD of T. mongolica would represent different units for conservation, as seed dispersal between populations is limited.

\section{Conclusion}

As expected, the rare species of T. mongolica possessed very low genetic variation at the cpDNA noncoding spacer. The effects of random genetic drift would lead to the loss of genetic variability in a small-sized population and genetic differentiation among populations, as observed in T. mongolica that has been mediated by limited seed dispersal and frequent population shrinking due to the flooding of the Yellow River. Phylogeographical analyses suggest that the present-day $T$. mongolica populations in Inner Mongolia were likely a result of restricted gene flow with isolation by distance plus occasional long distance dispersal. Molecular data provide sufficient information for reconstructing phylogeographical patterns and critical information for setting conservation strategy. For conservation considerations we suggest that populations with reciprocal monophyly at the cpDNA, and the two genetically highly variable populations likely represent management units for protecting T. mongolica.

\section{Methods}

\section{Population sampling}

In this study, we investigated the genetic variation and structure in the rare and endangered T. mongolica. This rare species is distributed in the western Inner Mongolia with small habitat fragments. Samples were collected from all populations, avoiding clonal individuals. A total of 77 individuals, representing eight extant populations, were sampled throughout the species entire range (Figure 1, Table 1). Individuals were chosen randomly. Young healthy leaves were collected from the field and were dried directly with silica gel. Dried leaves were preserved in silica gel until DNA extraction.

\section{DNA extraction and PCR}

Leaves were powdered in liquid nitrogen and stored in a $-70^{\circ} \mathrm{C}$ freezer. Genomic DNAs were extracted from the powdered tissue following a CTAB procedure and gelquantified [47]. The intergenic spacer between the $a t p \mathrm{~B}$ and $r b c \mathrm{~L}$ genes of the chloroplast DNA was amplified using a pair of universal primers [48]. Each $50 \mu \mathrm{L}$ PCR contained: $10 \mathrm{ng}$ template DNA, $5 \mu \mathrm{l} 10 \times$ PCR reaction buffer, $5 \mu \mathrm{L} \mathrm{MgCl}_{2}(25 \mathrm{mM}), 5 \mu \mathrm{dNTP}$ mix $(8 \mathrm{mM})$, 10 pmole of each primer, and $4 \mathrm{U}$ of Taq polymerase (Promega, Madison, USA). The reaction was programmed on an MJ Thermal Cycler with first cycle of denaturation at $95^{\circ} \mathrm{C}$ for $2 \mathrm{~min}$, then 30 cycles of denaturation at $94^{\circ} \mathrm{C}$ for $45 \mathrm{sec}$, annealing at $48^{\circ} \mathrm{C}$ for $1 \mathrm{~min}$, and extension at $72^{\circ} \mathrm{C}$ for $1 \mathrm{~min} 30 \mathrm{sec}$, followed by $72^{\circ} \mathrm{C}$ extension for $10 \mathrm{~min}$ and $4^{\circ} \mathrm{C}$ for storage.

\section{T-vector cloning and nucleotide sequencing}

All PCR products were purified from an agarose gel using the PCR product purification kit (Viogene, Sunnyvale, USA) and cloned into a pGEM-T easy cloning vector (Promega). For each $c p D N A a t p \mathrm{~B}-r b c \mathrm{~L}$ fragment, both strands were cycle-sequenced using the Taq Dye Deoxy Terminator Cycle Sequencing Kit (Applied Biosystem, Foster City, USA). Products of the cycle sequencing reactions were run on an ABI 377XL automated sequencer (Applied Biosystem). Cloned PCR products were sequenced using universal T7 forward (5'- TAATACGACTCACTATACGGG-3') and SP6 reverse (5'TATTTAGGTGACACTATAG-3') primers located on pGEM-T easy vector termination sites. Five clones for each individual were randomly chosen and sequenced.

\section{Sequence alignment and phylogenetic analysis}

The chloroplast DNA sequences were aligned with the program Clustal X 1.81 [49]. Indels were excluded from the data analysis. Neighbor-joining (NJ) analysis based on Kimura's [50] two-parameter distance was performed using the software MEGA 4.0 [51]. To evaluate clade support, 1,000 replicates of bootstrap analysis [52] were performed using fast heuristic search and TBR branchswapping. The nested clade analysis of Templeton et al. [53] provides a statistical framework for examining associations between the geographical distribution of haplotypes and their genealogical relationships $[54,55]$. Pairwise comparisons between DNA haplotypes were calculated using MEGA 4.0 [51]. These were used to construct a minimum spanning network in a hierarchical manner with the aid of the MINSPNET [56].

The nested clade analysis was accomplished by linking nucleotide haplotypes in a hierarchical manner based on mutational changes. The linking rules start at the tips of the cladogram and move one mutational step into the 
interior, uniting all haplotypes connected by this procedure into a ' 1 -step clade'. Following pruning off the initial 1-step clades from the tips, the procedure is repeated on the more interior portions of the haplotype tree until all haplotypes have been placed into 1-step clades. The next level of nesting uses the 1-step clades as units, rather than individual haplotypes. The linking rules are the same; however, '2-step clades' are now formed. The nesting procedure is repeated until a nesting level is reached such that the next higher nesting level would result in only a single category spanning the entire original haplotype network; via such hierarchical linking, a nested network was drawn.

\section{Population genetic analysis of the cpDNA}

Levels of inter- and intra-population genetic diversity based on cpDNA were quantified by indices of haplotype diversity $(h)$ [57] and estimates of nucleotide difference $(\theta)$ [58] using DnaSP (Version 5) [59]. Patterns of geographical subdivision and gene flow were also estimated hierarchically with the aid of DnaSP. Gene flow within and among regions or populations was approximated as $\mathrm{Nm}$, the number of female migrants per generation between populations. $N m$ was estimated using the expression $\mathrm{F}_{\mathrm{ST}}=$ $1 /(1+2 \mathrm{Nm})$, where $N$ is the female effective population size and $m$ is the female migration rate [60].

A model of "isolation by distance" was assessed by plotting pairwise $\mathrm{Nm}$ values against geographical distance [60]. The correlation between $\mathrm{Nm}$ and distance was determined by a regression of F-test over distances using SPSS program version 6.0 [61]. Geographical associations of haplotypes and clades within the minimum spanning network were tested using the program GeoDis [62]. Two statistics were calculated: 1) the clade distance, $D c$, a measure of the geographical spread of a clade, and 2) the nested clade distance, $D n$, a measure of the geographical distribution of a clade relative to other clades in the same higher level nesting category. These measures of geographical distribution were used to infer historical processes following the methods of Templeton et al. [53]. The nested clade analysis (NCA) has been recently challenged with serious flaws, such as ignorance of the type I error [63]. The debates [64-66] have been lasting. In this study, we used this analysis to generate a phylogeography hypothesis.

To estimate the population demographic trends for $T$. mongolica, we analyzed the cpDNA noncoding spacer data with BEAST v1.4 [67]. Bayesian skyline plot model was used to infer past demographic dynamics through time, which uses standard Markov chain Monte Carlo (MCMC) sampling procedures calculated from a sample of molecular sequences estimate a posterior distribution of effective population size without dependence on a pre-specified parametric model of demographic history
[68]. In the study, an evolutionary rate for the chloroplast $a t p B-r b c L$ spacer of $3 \times 10^{-9}$ substitutions per site per year was used $[69,70]$. The Bayesian skyline plot includes credibility intervals for the estimated effective population size at every point in time, back to the most recent common ancestor of the gene sequences. The credibility intervals represent both phylogenetic and coalescent uncertainty.

\section{Acknowledgements}

This study was supported by the National Science Council of Taiwan, and the CAS Important direction for knowledge innovation project of Chinese Academy of Sciences (No.KZCX2-EW-305).

\section{Author details}

'Key Laboratory of Plant Resources Conservation and Sustainable Utilization, South China Botanical Garden, Chinese Academy of Sciences, Guangzhou 510650, PR China. 'Department of Engineering Science, National ChengKung University, Tainan 701, Taiwan. ${ }^{3}$ Department of Biological Sciences, National Sun Yat-Sen University, Kaohsiung 804, Taiwan. ${ }^{4}$ Department of Life Sciences, National Cheng-Kung University, Tainan 701, Taiwan. ${ }^{5}$ Graduate Institute of Bioresources, Pingtung University of Science and Technology, Pingtung 912, Taiwan

\section{Authors' contributions}

TYC designed and conceived this study. XJG collected the samples and analyzed the data. WKW, ZHL, CCH, KHH and WHH collected the genetic data. WKW and TYC analyzed the data and wrote the manuscript. All authors read and approved the final manuscript.

Received: 18 March 2010 Accepted: 4 January 2011

Published: 4 January 2011

\section{References}

1. Frankham R, Ballou JD, Briscoe DA: Introduction to Conservation Genetics Cambridge, UK: Cambridge University Press; 2002.

2. Hamrick JL, Godt MJW: Conservation genetics of endemic plant species. In Conservation genetics: case histories from nature. Edited by: Avise JC, Hamrick JL. New York: Chapman and Hall; 1996:281-304.

3. Zhang YJ, Yang C: Comparative analysis of genetic diversity in the endangered shrub Tetraena mongolica and its related congener Zygophyllum xanthoxylon. Acta Phytoecologica Sinica 2000, 24:425-429.

4. Fu LG: The Red Book of Chinese Plants-Rare and Endangered Plants Beijing: Science Press; 1992.

5. Zhang YF, Yang C, Li B, Chen JK: Interpopulation difference in growth and reproduction of endemic species Tetraena mongolica in Ordos Plateau. Acta Ecologica Sinica 2003, 23:436-443.

6. Wang G, Lin Q, Xu Y: Tetraena mongolica Maxim can accumulate large amounts of triacylglycerol in phloem cells and xylem parenchyma of stems. Phytochemistry 2007, 68:2112-2117.

7. Liu GH, Zhou SQ, Thang L, Ren L: Study on the biological characteristics and the endangering factors of the Tetraena mongolica. J Inner Mongolia Forestry College 1993, 2:33-39.

8. Wang YC, Ma H, Zheng R: Studies on the reproductive characteristics of Tetraena mongolica Maxim. Acta Botanica Boreal Occident Sinica 2000, 20:661-665.

9. Xu Q, Jiang C, Liu S, Guo Q: Study on pollination ecology of endangered plant Tetraena mongolica population. Forest Res 2003, 16:391-397.

10. Ge XJ, Yu Y, Zhao NX, Chen HS, Qi WQ: Genetic variation in the endangered Inner Mongolia endemic shrub Tetraena mongolica Maxim. (Zygophyllaceae). Biol Conserv 2003, 111:427-434.

11. Moritz C: Uses of molecular phylogenies for conservation. Phil Trans $R$ Soc Lond B Biol Sci 1995, 349:113-118.

12. Moritz C, Faith DP: Comparative phylogeography and the identification of genetically divergent areas for conservation. Mol Ecol 1998, 7:419-429.

13. Haig SM: Molecular contributions to conservation. Ecology 1998 79:413-425. 
14. Ouborg NJ, Piquot Y, van Groenendael JM: Population genetics, molecular markers and the study of dispersal of plants. J Ecol 1999, 87:551-568.

15. Provan J, Powell W, Hollingsworth PM: Chloroplast microsatellites: new tools for studies in plant ecology and evolution. Trends Ecol Evol 2001, 16:142-147.

16. Chiang TY, Hung KH, Hsu TW, Wu WL: Lineage sorting and phylogeography in Lithocarpus formosanus and L. dodonaeifolius (Fagaceae) from Taiwan. Ann Mo Bot Gard 2004, 91:207-222.

17. Huang JC, Wang WK, Peng Cl, Chiang TY: Phylogeography and conservation genetics of Hygrophila pogonocalyx (Acanthaceae) based on atpB-rbcL noncoding spacer cpDNA. J Plant Res 2005, 118:1-11.

18. Kanno M, Yokoyama J, Suyama Y, Ohyama M, Itoh T, Suzuki M: Geographical distribution of two haplotypes of chloroplast DNA in four oak species (Quercus) in Japan. J Plant Res 2003, 116:311-317.

19. Birky CW: The inheritance of genes in mitochondria and chloroplasts: Laws, mechanisms, and models. Ann Rev Genet 2001, 35:125-148.

20. Cruzan MB, Templeton AR: Paleoecology and coalescence: phylogeographic analysis of hypotheses from the fossil record. Trends Ecol Evol 2000, 15:491-496.

21. Orive ME, Asmussen MA: The effects of pollen and seed migration on nuclear-dicytoplasmic systems. II. A new method for estimating plant gene flow from joint nuclear-cytoplasmic data. Genetics 2000, 155:833-854.

22. Song $B H$, Wang $X Q$, Wang $X R$, Sun $L$, Hong DY, Peng PH: Maternal lineages of Pinus densata, a dipoid hybrid. Mol Ecol 2002, 11:1057-1063.

23. Moritz C: Defining 'evolutionarily significant units' for conservation. Trends Ecol Evol 1994, 9:373-375

24. Li WH: Molecular evolution Sinauer: Sunderland; 1997.

25. Lü XM, Fu YX, Zhang YP: Evolution of mitochondrial cytochrome B pseudogene in genus Nycticebus. Mol Biol Evol 2002, 19:2337-2341.

26. Ge XJ, Chiang YC, Chou CH, Chiang TY: Nested clade analysis of Dunnia sinensis (Rubiaceae), a monotypic genus from China based on organelle DNA sequences. Conserv Genet 2002, 3:351-362.

27. Lu SY, Peng Cl, Cheng YP, Hong KH, Chiang TY: Chloroplast DNA phylogeography of Cunninghamia konishii (Cupressaceae), an endemic conifer of Taiwan. Genome 2001, 44:797-807.

28. Huang S, Chiang YC, Schaal BA, Chou CH, Chiang TY: Organelle DNA phylogeography of Cycas taitungensis, a relict species in Taiwan. Mol Ecol 2001, 10:2669-2681.

29. Zhen JH, Liu GH: Research advance in rare and endemic plant Tetraena mongolica Maxim. Chin J Appl Ecol 2008, 19:433-440.

30. Zietkiewicz E, Rafalski A, Labuda D: Genome fingerprinting by Simple Sequence Repeat (SSR)-anchored polymerase chain reaction amplification. Genomics 1994, 20:176-183.

31. Sinclair K: The Yellow River: A 5000 Year Journey Through China Chatswood, Sydney, Australia: Child \& Associates Publishing; 1987

32. Leung G: Reclamation and Sediment Control in the Middle Yellow River Valley. Water International 1996, 21:12-19.

33. Barker JS, Frydenberg J, González J, Davies HI, Ruiz A, Sørensen JG, Loeschcke V: Bottlenecks, population differentiation and apparent selection at microsatellite loci in Australian Drosophila buzzatii. Heredity 2009, 102:389-401.

34. Whitehouse AM, Harley EH: Post-bottleneck genetic diversity of elephant populations in South Africa, revealed using microsatellite analysis. $\mathrm{Mol}$ Ecol 2001, 10:2139-2149.

35. Hanski IA, Gilpin ME: Metapopulation biology: ecology, genetics, and evolution Orlando: Academic Press; 1997.

36. Fischer $M$, Matthies D: Mating structure and inbreeding and outbreeding depression in the rare plant Gentianella germanica (Gentianaceae). Am J Bot 1997, 84:1685-1692.

37. Reed DH, Frankham R: Correlation between fitness and genetic diversity. Conserv Biol 2003, 17:230-237.

38. Frankel $\mathrm{OH}$ : The place of management in conservation. In Genetics and Conservation. Edited by: Schonewald-Cox CM, Chambers SM, MacBryde B, Thomas L. Menlo Park, Calif: Benjamin-Cummings; 1983:1-14.

39. Hewitt GM: Some genetic consequences of ice ages, and their role in divergence and speciation. Biol J Linn Soc 1996, 58:247-276.

40. Ledig FT, Hodgskiss PD, Jacob-Cervantes V: Genetic diversity, mating system, and conservation of a Mexican subalpine relict, Picea mexicana Martinez. Conserv Genet 2002, 3:113-122.
41. Nakagawa M: Genetic diversity of fragmented populations of Polygala reinii (Polygalaceae) a perennial herb endemic to Japan. J Plant Res 2004, 117:355-361.

42. Ryder OA: Species conservation and systematics: the dilemma of subspecies. Trends Ecol Evol 1986, 1:9-10.

43. Waples RS: Pacific Salmon, Oncorhynchus spp. and the definition of "species" under the endangered species act. Mar Fish Rev 1991, 53:11-22.

44. Crandall KA, Bininda-Emonds OR, Mace GM, Wayne RK: Considering evolutionary processes in conservation biology. Trends Ecol Evol 2000, 15:290-295.

45. Aoki K, Suzuki T, Hsu TW, Murakami N: Phylogeography of the component species of broad-leaved evergreen forests in Japan, based on chloroplast DNA. J Plant Res 2004, 117:77-94.

46. Rader RB, Belk MC, Shiozawa DK, Crandall KA: Empirical tests for ecological exchangeability. Anim Conserv 2005, 8:239-247.

47. Doyle JJ, Doyle JL: A rapid isolation procedure for small quantities of fresh leaf tissue. Phytochem Bull 1987, 19:11-15.

48. Chiang TY, Schaal BA, Peng Cl: Universal primers for amplification and sequencing a noncoding spacer between $a t p B$ and $r b c L$ genes of chloroplast DNA. Bot Bull Acad Sin 1998, 39:245-250.

49. Thompson JD, Gibson TJ, Plewniak F, Jeanmougin F, Higgins DG: The Clustal X windows interface: flexible strategies for multiple sequence alignment aided by quality analysis tools. Nucleic Acids Res 1997, 24:4876-4882.

50. Kimura M: A simple method for estimating evolutionary rates of base substitutions through comparative studies of nucleotide sequences. Mol Evol 1980, 16:111-120.

51. Tamura K, Dudley J, Nei M, Kumar S: MEGA4: Molecular Evolutionary Genetics Analysis (MEGA) software version 4.0. Mol Biol Evol 2007, 24:1596-1599.

52. Felsenstein J: Confidence limits on phylogenies: an approach using the bootstrap. Evolution 1985, 39:783-791.

53. Templeton AR, Routman E, Phillips CA: Separating population structure from population history: a cladistic analysis of the geographical distribution of mitochondrial DNA haplotypes in the tiger salamander, Ambystoma tigrinum. Genetics 1995, 140:767-782.

54. Templeton AR: Nested clade analyses of phylogeographic data: testing hypotheses about gene flow and population history. Mol Ecol 1998 7:381-397

55. Avise JC: Phylogeography: the history and formation of species Cambridge: Harvard University Press; 2000.

56. Excoffier L, Smouse PE: Using allele frequencies and geographic subdivision to reconstruct gene trees within a species: molecular variance parsimony. Genetics 1994, 136:343-359.

57. Nei M, Tajima F: Maximum likelihood estimation of the number of nucleotide substitutions from restriction sites data. Genetics 1983, 105:207-217.

58. Watterson GA: On the number of segregating sites in genetical models without recombination. Theor Pop Biol 1975, 7:256-276.

59. Librado P, Rozas J: DnaSP v5: A software for comprehensive analysis of DNA polymorphism data. Bioinformatics 2009, 25:1451-1452.

60. Slatkin M: Isolation by distance in equilibrium and nonequilibrium populations. Evolution 1993, 47:264-279.

61. Noruis MJ: SPSS for Windows, version 6.0 Englewood Cliffs: Prentice Hall; 1994.

62. Posada D, Crandall KA, Templeton AR: GeoDis: a program for the cladistic nested analysis of the geographical distribution of genetic haplotypes. Mol Ecol 2000, 9:487-488

63. Knowles LL, Maddison WP: Statistical phylogeography. Mol Ecol 2002 11:2623-2635.

64. Knowles LL: Why does a method that fails continue to be used? Evolution 2008, 62:2713-2717.

65. Templeton AR: Why does a method that fails continue to be used? The answer. Evolution 2009, 63:807-812.

66. Templeton AR: Statistical hypothesis testing in intraspecific phylogeography: nested clade phylogeographic analysis vs. approximate Bayesian computation. Mol Ecol 2009, 18:319-331.

67. Drummond AJ, Rambaut A: BEAST: Bayesian evolutionary analysis by sampling trees. BMC Evol Biol 2007, 7:214 
68. Drummond AJ, Rambaut A, Shapiro B, Pybus OG: Bayesian coalescent inference of past population dynamics from molecular sequences. $\mathrm{Mol}$ Biol Evol 2005, 22:1185-1192.

69. Wolfe KH, Sharp PM, Li WH: Rates of nucleotide substitution vary greatly among plant mitochondrial, chloroplast, and nuclear DNAs. Proc Natl Acad Sci USA 1987, 84:9054-9058.

70. Graur D, Li WH: Fundamentals of molecular evolution Sunderland, Massachusetts: Sinauer Press; 2000.

Submit your next manuscript to BioMed Central and take full advantage of:

- Convenient online submission

- Thorough peer review

- No space constraints or color figure charges

- Immediate publication on acceptance

- Inclusion in PubMed, CAS, Scopus and Google Scholar

- Research which is freely available for redistribution

Submit your manuscript at www.biomedcentral.com/submit
() Biomed Central 